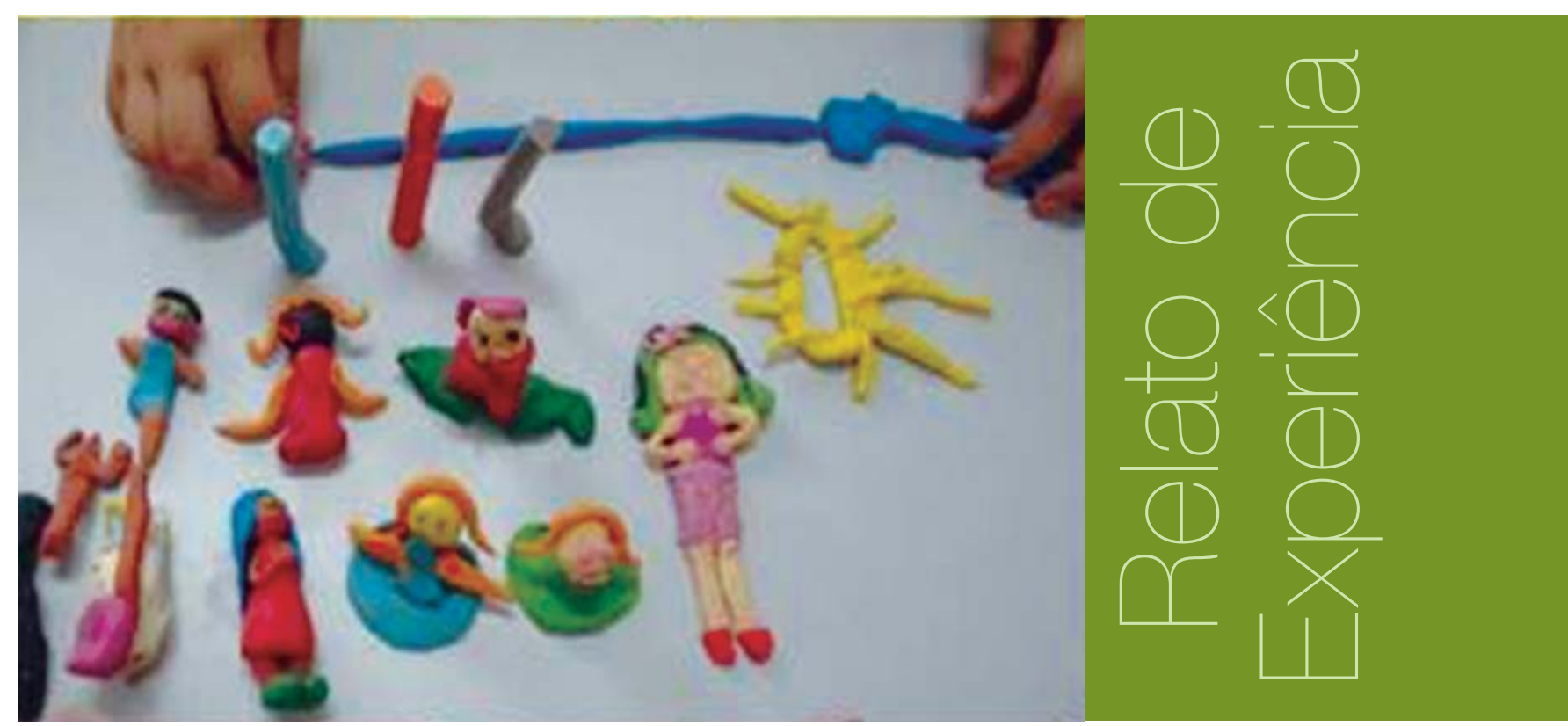

\title{
Grupo de dinâmicas
}

com crianças na Clínica

Psicológica da Universidade Estadual de Londrina

\author{
Luzia Venâncio Zanluqui' - luziazanluqui@gmail.com \\ Maria Lúcia Mantovanelli Ortolan² - ortolan78@gmail.com \\ Stéfanie Bittencourt Ribas Fornasier ${ }^{3}$ - stfornasier19@gmail.com \\ Maíra Bonafé Sei - mairabonafe@gmail.com
}

\section{RESUMO}

A Clínica Psicológica da Universidade Estadual de Londrina (UEL) realiza, desde 2015, o projeto extensionista Grupo de Dinâmicas, sobre 0 qual se refere este estudo. Trata-se de um relato de experiência que objetiva uma discussão acerca do grupo de dinâmicas infantil, de caráter aberto, ofertado a crianças de até 11 anos. Na experiência ora relatada, notaram-se mudanças nos participantes, expostas pelas próprias crianças ou relatadas pelos pais, o que indica possíveis contribuições do grupo para a promoção de saúde dessa população.

\section{PALAVRAS-CHAVE}

Grupo de dinâmicas. Serviços de saúde infantil. Serviço-escola de Psicologia. Extensão universitária.

\section{ABSTRACT}

The Psychological Clinic of the State University of Londrina offers since 2015 dynamic groups, open do enrollees on the waiting list and other interested in these activities. This is an experience report that aims to present and discuss the experience of group dynamics of child, that have an open character, addressed

\footnotetext{
1 Discente de Psicologia da UEL

2 Discente de Psicologia da UEL; Bolsista de Iniciação Extensionista - PROEX-UEL

3 Discente de Psicologia da UNIFIL; Estagiária da Clínica Psicológica da UEL

4 Psicóloga, Mestre e doutora em Psicologia Clínica pelo IP-USP, Professora Adjunta do Departamento de Psicologia e Psicanálise - UEL
} 
to children under 11 years of age. It was noted changes in the participants, exposed by the children themselves or reported by parents, with group contributions to the promotion of health of this population.

\section{PALAVRAS-CHAVE}

Group of dynamics. Child Health Services. Psychology university clinic. University Extension.

\section{Relato de experiência}

Este artigo almeja discutir uma prática extensionista desenvolvida na Clínica Psicológica da UEL. Discorre-se sobre a proposta e os resultados obtidos por meio do Grupo de Dinâmicas, projeto de extensão vinculado ao Departamento de Psicologia e Psicanálise da Universidade Estadual de Londrina, inicialmente intitulado "Grupo de Espera".

0 objetivo do grupo consiste no acolhimento de inscritos na lista de espera para psicoterapia individual. Sua proposta foi inspirada nos grupos de espera desenvolvidos em outros serviçosescola de Psicologia do país (GUERRELHAS; BUENO; SILVARES, 2000; GUERRELHAS; SILVARES, 2000). Tais grupos foram criados para lidar com a longa espera entre a inscrição e o efetivo início da psicoterapia em serviços-escola de Psicologia, ainda que não tivessem finalidade psicoterapêutica.

Apesar de a ideia inicial do grupo ser 0 acolhimento de inscritos na lista de espera, optou-se por ampliar a participação, aceitando indivíduos da comunidade interna e externa à universidade, que não necessariamente estejam esperando para participar da psicoterapia individual. Desse modo, a atividade ofertada passou a adquirir uma nova e mais abrangente configuração, tendo sua denominação alterada para Grupo de Dinâmicas.

0 oferecimento dessa atividade se organiza, na Clínica Psicológica da UEL, a partir de três tipos de grupos: Grupo para Crianças, de até 11 anos; Grupo para Adolescentes, de até 17 anos e o Grupo para Adultos, a partir de 18 anos. Para apresentação da proposta aos possíveis interessados, são feitas divulgações, tanto para a comunidade universitária quanto para a comunidade externa, que ocorrem por meio de cartazes, notas em jornal, TV e rádio universitária, além de ligações telefônicas para aqueles que aguardam na lista de espera para triagens.

Os grupos acontecem semanalmente nos períodos matutino, vespertino e noturno. Os horários foram estabelecidos para atender às particularidades de cada público. No caso das crianças, os horários disponíveis são manhã e tarde. Optou-se pela oferta de um grupo para adultos concomitante ao grupo de crianças, a fim de atender os pais que aguardam o término do horário da atividade dos filhos sem, contudo, se restringir aos pais.

As atividades realizadas são das mais diversas, podendo ser ilustradas, dentre outras, pela modelagem de bonecos para representação das diferenças entre as pessoas e pela construção de objetos para simbolização dos lugares que as crianças mais gostam (Figura 1). Essas atividades visam à simbolização e à reflexão sobre as vivências dos participantes a respeito das diferenças.

Figura 1: Massinhas de modelar - " 0 que as pessoas

têm em comum?" e "0

espaço que mais gosto".

Fonte: Dados desta pesquisa
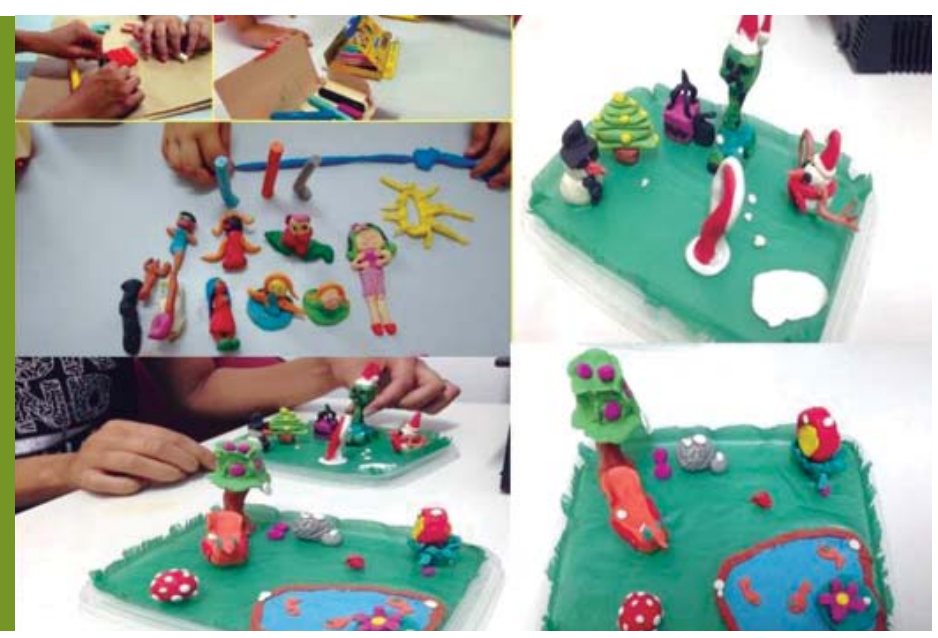
Esclarece-se que a formatação dos grupos de dinâmicas segue a proposta de grupos abertos, sem uma finalidade, a priori, psicoterapêutica (ZIMERMAN, 2000). Todavia, por meio da experiência prática nesses grupos foram notados ganhos terapêuticos para os usuários. Percebeu-se que medos puderam ser expostos e que dúvidas foram sanadas a partir das atividades propostas. Em seus relatos, as crianças verbalizaram: "eu tinha medo de zumbis e guerra, agora nem tenho mais"; "Agora eu sei por que meninos e meninas são diferentes".

Os pais também comentam que os filhos apresentaram mudanças comportamentais. Como a mãe de Marília (nome fictício), participante do grupo vespertino, que, após interromper a frequência por algumas semanas, levou novamente a filha e disse: "parei porque parei mesmo, não quis mais me deslocar até aqui, mas tive que voltar a trazê-la... ela começou a piorar, ela estava tão bem quando eu trazia ela, daí estou voltando né" (sic).

Alguns pais passaram a propor atividades, e outros relataram que seus filhos estavam modificando certas condutas frente a eventos ante os quais agiam de maneira inadequada. Esses relatos de possíveis ganhos terapêuticos proporcionados pelas atividades dos grupos contribuem para compreender esse tipo de ação como promotora de saúde mental (BRASIL, 2014). Nessa perspectiva, quando uma atividade é proposta, sempre há o cuidado de se pensar em intervenções que, além do caráter lúdico, tenham como foco o desenvolvimento social, educativo e emocional (Figura 2).

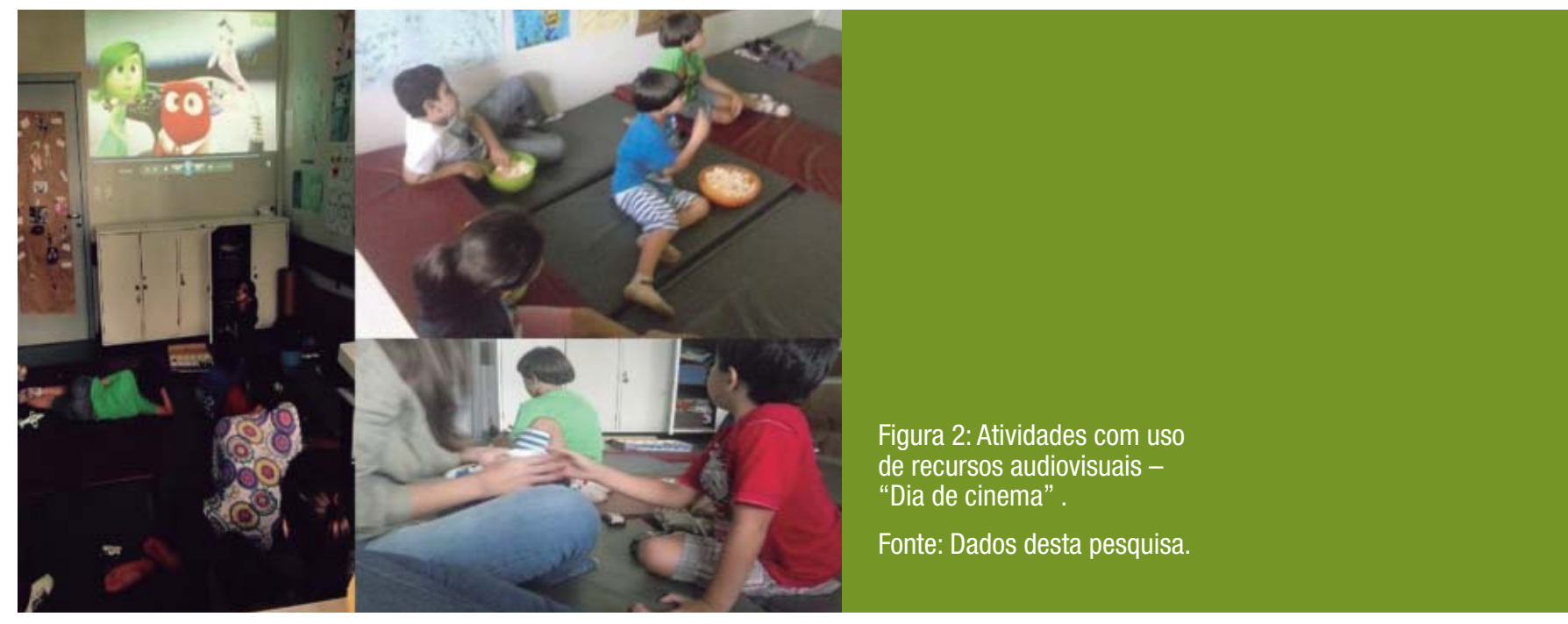

Dessa forma, busca-se escolher vídeos, músicas e materiais em geral que possibilitem 0 desenvolvimento de uma atividade mais reflexiva na sequência. Um exemplo foi a utilização de um filme sobre emoções básicas para trabalhar os sentimentos e de outro, sobre uma zebrinha com listras diferentes, para trabalhar a questão da diversidade (Figura 3).

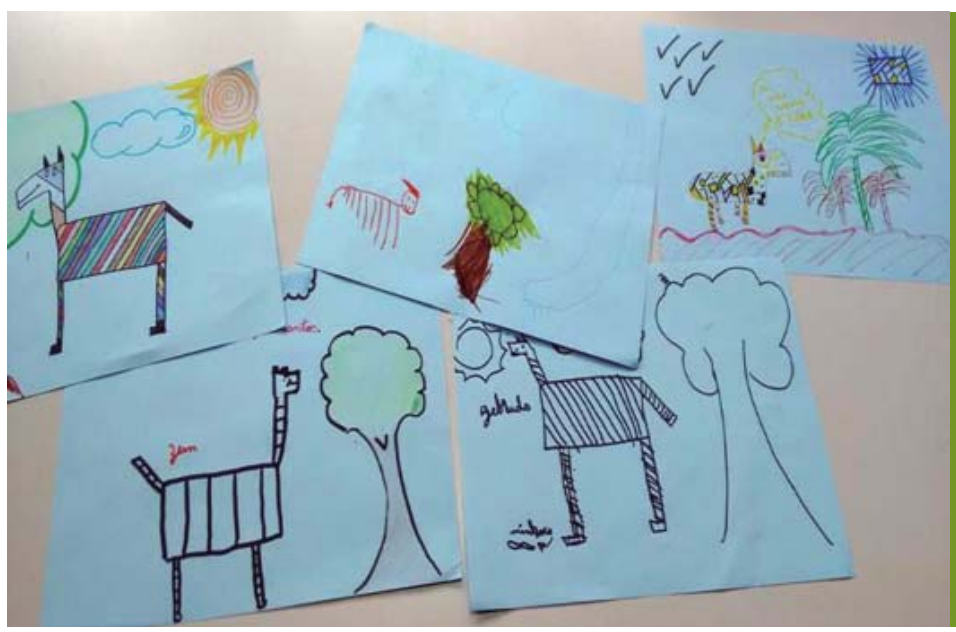

Figura 3: Uso de material gráfico - desenho sobre "As diferenças"

Fonte: Dados desta pesquisa 
Quanto aos recursos utilizados nos grupos, além dos audiovisuais e gráficos, ficam disponíveis brinquedos, colchonetes, mesas para atividades, dentre outros, que são escolhidos mediante o tema a ser trabalhado em cada semana. Devido ao fato de os grupos infantis diferirem entre si quanto ao tipo de público que os frequenta, em termos de idade e necessidades especiais, as atividades realizadas procuram contemplar essas peculiaridades, com 0 intuito de criar um ambiente no qual cada criança se sinta participante e atuante nesse meio.

De modo geral, observa-se que, se por um lado, o grupo aberto se apresenta como uma porta de entrada para a população interessada em intervenções psicológicas, por outro, ele carrega algumas complexidades. Uma delas vincula-se à heterogeneidade dos participantes, algo característico de um grupo aberto, mas que pode ser visto por alguns profissionais como uma dificuldade para 0 desenvolvimento da intervenção. Neste sentido, aponta-se para Zimerman (2000), que indica ser importante haver uma "homogeneidade quanto aos limites da faixa etária" (p. 157), e para Levisky (1997), defensor de que as crianças possam ser divididas em idades de 6 a 9 anos e 9 a 12 anos, algo que não é possível de ser feito no grupo de dinâmicas descrito.

Esse tipo de grupo apresenta limites, situados no fato de não objetivar obtenção de insight e mudanças estruturais de personalidade, haja vista não ter uma finalidade psicoterapêutica (ZIMERMAN, 2000). Ao mesmo tempo, proporciona uma aprendizagem por meio de vivências e do contato social e permite 0 exercício e 0 desenvolvimento da criatividade, promovendo, ao mesmo tempo, a plasticidade psíquica (FERREIRA; CAMPOS, 2014; MEIRA, 2012; SCHMIDT \& NUNES, 2014) e a saúde emocional dos participantes (WINNICOTT, 1975).

Considera-se que o grupo em questão se tornou um tipo de intervenção psicológica que, além de atender à demanda de espera, permite uma vinculação do público com a clínica e com a própria universidade, favorecendo a aproximação da população com o serviço psicológico. Ele contribuiu, ademais, para desmistificar estereótipos atribuídos aos usuários de serviços de saúde mental muito presentes na cultura popular local.

\section{Referências}

BRASIL. Portaria № 2.446, de 11 de novembro de 2014. Redefine a Política Nacional de Promoção da Saúde (PNPS). Brasília: Ministério da Saúde, 2014. Disponível em: http:// bvsms.saude.gov.br/bvs/saudelegis/gm/2014/prt2446_11_11_2014.html. Data de acesso em 27 fevereiro 2016.

FERREIRA, Luzia Janaina Soares; CAMPOS, Marcelo. 0 brincar e sua função no processo analítico infantil. Connection Line, n. 11, 2014.

GUERRELHAS, Fabiana; BUENO, Mariana; SILVARES, Edwiges Ferreira de Mattos. Grupo de ludoterapia comportamental $X$ Grupo de espera recreativo infantil. Revista brasileira de terapia comportamental e cognitiva, v. 2, n. 2, p. 157-169, 2000.

GUERRELHAS, Fabiana Ferreira; SILVARES, Edwiges Ferreira de Mattos. Grupos de espera recreativos: proposta para diminuir o índice de evasão em clínica-escola de psicologia. Temas em Psicologia da SBP, v. 8, n. 3, p. 313-321, 2000.

LEVISKY, R. B. Grupo com crianças. In: ZIMERMAN, D. E.; OSORIO, L. C. Como trabalhamos com grupos. Porto Alegre: Artes Médicas, 1997. p. 311-320.

MEIRA, Ana Marta. A educação, o brincar e a infância contemporânea. Revista de Educação PUC-Campinas, v. 17, n. 2, 2012.

SCHMIDT, Marília Bordin; NUNES, Maria Lúcia Tiellet. 0 Brincar como Método Terapêutico na Prática Psicanalítica: Uma Revisão Teórica. Revista de Psicologia, v. 6, n. 1, p. 18-24, 2014.

WINNICOTT, D. W. 0 brincar e a realidade. Rio de Janeiro: Imago, 1975.

ZIMERMAN, D. E. Fundamentos básicos das grupoterapias. Porto Alegre: Artmed, 2000. 